\title{
An antibody based approach for multi-coloring osteogenic and chondrogenic proteins in tissue engineered constructs
}

Citation for published version (APA):

Leferink, A. M., Reis, D. S., van Blitterswijk, C. A., \& Moroni, L. (2018). An antibody based approach for multi-coloring osteogenic and chondrogenic proteins in tissue engineered constructs. Biomedical Materials, 13(4), [044102]. https://doi.org/10.1088/1748-605X/aab51e

Document status and date:

Published: 01/07/2018

DOI:

10.1088/1748-605X/aab51e

Document Version:

Publisher's PDF, also known as Version of record

Document license:

Taverne

Please check the document version of this publication:

- A submitted manuscript is the version of the article upon submission and before peer-review. There can be important differences between the submitted version and the official published version of record.

People interested in the research are advised to contact the author for the final version of the publication, or visit the DOI to the publisher's website.

- The final author version and the galley proof are versions of the publication after peer review.

- The final published version features the final layout of the paper including the volume, issue and page numbers.

Link to publication

\footnotetext{
General rights rights.

- You may freely distribute the URL identifying the publication in the public portal. please follow below link for the End User Agreement:

www.umlib.nl/taverne-license

Take down policy

If you believe that this document breaches copyright please contact us at:

repository@maastrichtuniversity.nl

providing details and we will investigate your claim.
}

Copyright and moral rights for the publications made accessible in the public portal are retained by the authors and/or other copyright owners and it is a condition of accessing publications that users recognise and abide by the legal requirements associated with these

- Users may download and print one copy of any publication from the public portal for the purpose of private study or research.

- You may not further distribute the material or use it for any profit-making activity or commercial gain

If the publication is distributed under the terms of Article $25 \mathrm{fa}$ of the Dutch Copyright Act, indicated by the "Taverne" license above, 


\title{
Biomedical Materials
}

PAPER

CrossMark

\section{An antibody based approach for multi-coloring osteogenic and chondrogenic proteins in tissue engineered constructs}

20 February 2018

ACCEPTED FOR PUBLICATION

8 March 2018

PUBLISHED

11 April 2018

\author{
Anne M Leferink ${ }^{1,2,4}$, Diogo Santos Reis ${ }^{1,4}$, Clemens A van Blitterswijk ${ }^{1,3}$ and Lorenzo Moroni ${ }^{1,3}$ (1) \\ 1 Department of Tissue Regeneration, MIRA institute, University of Twente, The Netherlands \\ 2 BIOS-Lab on a chip group, MIRA institute, University of Twente, The Netherlands \\ Department of Complex Tissue Regeneration, Maastricht University, The Netherlands \\ 4 Shared first author. \\ E-mail:1.moroni@maastrichtuniversity.nl \\ Keywords: scaffolds, molecular probes, tissue engineering, imaging \\ Supplementary material for this article is available online
}

\begin{abstract}
When tissue engineering strategies rely on the combination of three-dimensional (3D) polymeric or ceramic scaffolds with cells to culture implantable tissue constructs in vitro, it is desirable to monitor tissue growth and cell fate to be able to more rationally predict the quality and success of the construct upon implantation. Such a 3D construct is often referred to as a 'black-box' since the properties of the scaffolds material limit the applicability of most imaging modalities to assess important construct parameters. These parameters include the number of cells, the amount and type of tissue formed and the distribution of cells and tissue throughout the construct. Immunolabeling enables the spatial and temporal identification of multiple tissue types within one scaffold without the need to sacrifice the construct. In this report, we concisely review the applicability of antibodies (Abs) and their conjugation chemistries in tissue engineered constructs. With some preliminary experiments, we show an efficient conjugation strategy to couple extracellular matrix Abs to fluorophores. The conjugated probes proved to be effective in determining the presence of collagen type I and type II on electrospun and additive manufactured 3D scaffolds seeded with adult human bone marrow derived mesenchymal stromal cells. The conjugation chemistry applied in our proof of concept study is expected to be applicable in the coupling of any other fluorophore or particle to the Abs. This could ultimately lead to a library of probes to permit high-contrast imaging by several imaging modalities.
\end{abstract}

\section{Introduction}

Tissue engineering approaches for cartilage and bone regeneration often involve the use of three-dimensional (3D) synthetic polymeric or ceramic scaffolds with a certain mechanical integrity to mimic the natural native environment. Scaffolds can be implanted directly into the defect site, in which they are expected to attract cells and facilitate tissue ingrowth. Another approach is based on in vitro culture of scaffolds combined with autologous (stem) cells to be able to control culture parameters and therewith steer the cell fate and tissue growth into a desired lineage. In both cases, our understanding of the biological phenomena occurring within the pore network of 3D scaffolds is often limited. Real time monitoring of such phenomena offers a tool to also advance the design of scaffolds which can better control cell fate and tissue growth. In particular, monitoring and being able to discriminate between different types of collagen would be important to further understand tissue morphogenesis in scaffolds. Collagen is the most abundant protein in mammals, representing about $30 \%$ of the total protein mass. There are currently 28 different collagen types discovered. Collagen type I is the most common and can be found in several tissues, while collagen type II is most found in articular cartilage [1]. However, current imaging techniques are hindered by the scaffolds limited transparency, scaffolds geometry and a lack of available methods to non-invasively assess cells and tissues functionality [2].

In the past few decades, the need for non-invasive monitoring methods has been widely acknowledged. 


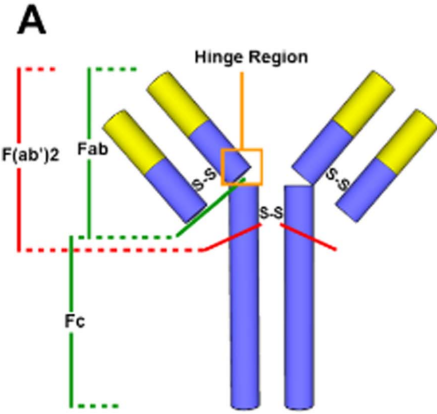

C

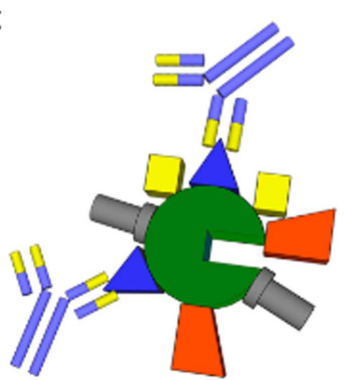

B
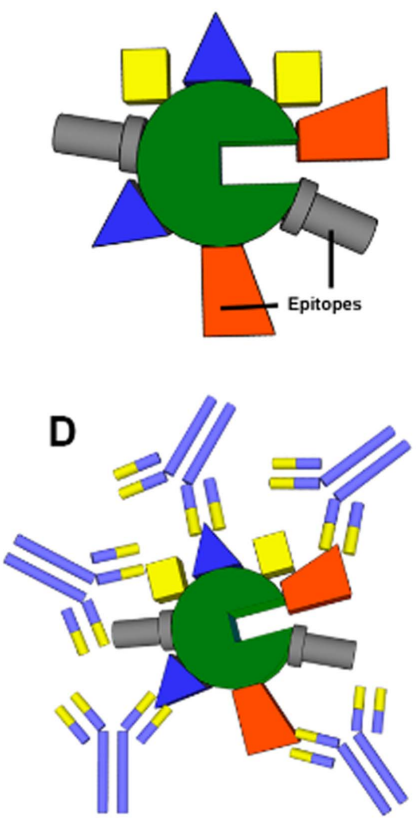

E
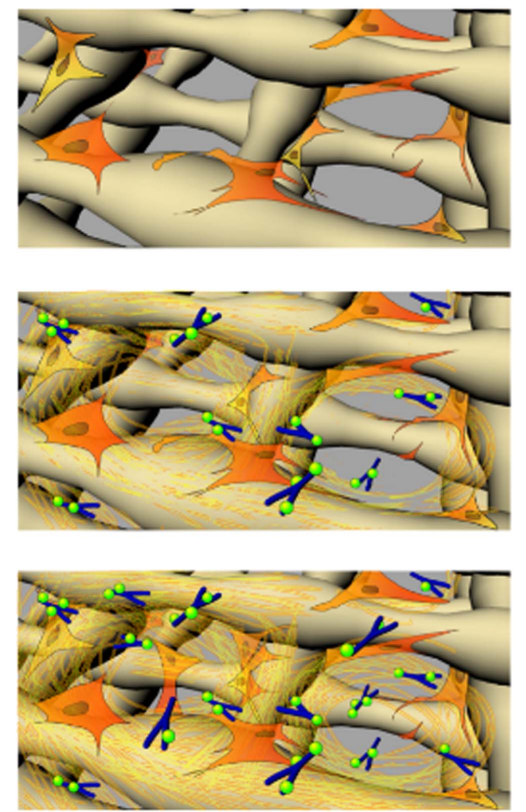

Figure 1. A schematic representation of an immunoglobulin $\mathrm{G}(\mathrm{IgG})$ antibody. IgG is a single protein made from four peptides joined by disulfide bonds (A). There is a single constant region containing the Fc portion and species-specific antigens. The variable region contains the Fab portion that binds the epitope portion of the antigen (B). Monoclonal antibodies react with a specific epitope of an antigen (C) while polyclonal antibodies react with various epitopes (D). Fluorescent labeled Abs can enable the localization of specific biological components within $3 \mathrm{D}$ tissue engineering constructs over time (E), from top to bottom increasing in culture time. Figures are not to scale.

Several imaging methods have been opted to overcome transparency issues, such as ultrasound, nuclear, photoacoustic, $\mathrm{x}$-ray and magnetic resonance (MR) based imaging modalities [3]. X-ray and MR imaging have shown to be promising tools in quantification of mineralization in bone tissue engineering $[4,5]$. However, to date none of these methods enables the detection of multiple early tissue lineage markers with a single cell-resolution in 3D without the need to combine several imaging modalities.

The evolution of bio-conjugation chemistry has significantly contributed to the development of novel and successful methods to label multiple components within a single construct for imaging purposes. Antibodies (Abs) stand out as probes due to their specificity, affinity and versatility to target tissue specific components. Abs are proteins belonging to the immunoglobulin group and one of the most important defense mechanisms in vertebrate animals. In research, they are used as highly specific probes in order to identify and locate intra- and extracellular proteins, differentiate cell types and separate proteins [6]. Immunoglobulins are made from two identical heavy chain $(H, 55-70 \mathrm{kDa}$, either $\kappa$ or $\lambda)$ and two identical light chain $(L, 24-25 \mathrm{kDa}$, either $\gamma, \varepsilon, \delta, \alpha$, or $\mu$ ) peptides joined by disulfide bonds (figure $1(\mathrm{~A})$ ). The Fc portion of Abs is constant and specific to the animal in which the antibody is generated while the Fab portion is variable and binds to the epitope part of the antigen. A single antigen has multiple epitopes (figure 1(B)) to allow Abs to recognize it. Monoclonal antibodies are homogeneous and bind to a single epitope on the antigen (figure $1(\mathrm{C})$ ), whereas polyclonal antibodies are immunochemically dissimilar, having affinities to various epitopes of the same antigen (figure 1(D)). A possible application of Ab-based extracellular matrix (ECM) detection in $3 \mathrm{D}$ tissue engineered scaffolds is schematically presented in figure 1(E). Initially, only cells are present in the in vitro culture (upper figure). Over time, the cells will start to secrete specific ECM components such as collagen to which a targeted label will bind. With increasing concentration of ECM components, the binding of labeled Abs will also increase, resulting in a higher overall brightness of the substrate upon optical detection.

The direct conjugation of antibodies to detectable labels or agents allows the combination of the label properties with the high specificity and selectivity of antibodies [7]. Three main label types can be distinguished: Ab [8-11] or enzymes [12, 13] based detection with fluorophores, or particulate based labeling $[6,14]$. Fluorescent immuno-labels enable the detection of specific components qualitatively and quantitatively by detecting light emitted from a fluorophore with a different wavelength than the light used to excite the fluorophore [6]. Antibody conjugated particles were developed already decades ago for the immunolabeling of specific ECM components in scanning electron microscopy analysis, although the required 
sample processing made real-time monitoring impossible [14]. To date, particle based labels comprise a wide range of materials from heavy metals such as colloidal gold or small gold particles [14-16] to magnetic beads [17-19], radioactive components [9, 20, 21] and combinations of, for example, microbeads and covalently bound or entrapped fluorescent moieties [22].

The reactivity of an antibody is similar as for proteins determined by its amino acid composition and tertiary structure [23]. Understanding the functional groups available on an antibody is vital for finding the most appropriate conjugation method. Most Ab labeling strategies use one of the three types of available reactive groups. These groups comprise primary amines $\left(-\mathrm{NH}_{2}\right)$, sulfhydryl groups $(-\mathrm{SH})$ and carbohydrates (sugars) [24, 25]. Primary amines are the most commonly used groups for conjugation, since they are abundant, widely distributed and easily modified due to their reactivity and location on the surface of the antibody [26]. The N-hydroxysuccinimidyl ester (NHS ester) reactive group is the most specific and efficient reagent to target primary amines [26]. The only drawback of this strategy is that it may cause a significant decrease in the antigen-binding activity of the antibody [27]. This is due to the presence of primary amines in that site, which can also be modified. Moreover, lysines, on which primary amines can be found, have a positive net charge while fluorophores have negative net charge, which may alter antibody conformation and activity upon conjugation. This decrease in activity is particularly noticeable when working with monoclonal antibodies or when attempting to achieve a higher degree of labeling (DOL) [23]. The second possible target labeling Abs is via sulfhydryls. Disulfide bonds are important in $\mathrm{Ab}$ function as they contribute to covalently connect the two Ab halves at the hinge region. Because disulfides in the hinge region are the most susceptible to reduction, a commonly utilized method to cleave these disulfides bridges is by introducing papain [23]. Papain induced cleavage splits the antibody into monovalent halves without changing the antigen-binding site and ensures consistent labeling at a defined location and degree. The third useful target for labeling nanoparticles with antibodies is carbohydrate moieties [23]. Labeling carbohydrates requires more steps than labeling amines because carbohydrates must first be oxidized to obtain reactive aldehydes. Recently, Shrestha et al performed an extensive study on the application of the three previously mentioned conjugation methods to conjugate a specific Ab to one type of fluorophore [23]. They concluded that amine based conjugation was by far the best technique due to its simplicity, rapidity, ease of operation, higher conjugate yield and lower costs. To enable the direct coupling of a label to the $\mathrm{Ab}$ via $-\mathrm{NH}_{2},-\mathrm{SH}$ or $-\mathrm{CHO}$ groups to form a detectable $\mathrm{Ab}$, functionalization of the label and/or $\mathrm{Ab}$ is required. Several well-known strategies to couple a label covalently to the reactive groups of the $A b$ are via maleimide activation, active ester formation and biotin-avidin or biotin-streptavidin coupling [28, 29]. Furthermore, some non-covalently coupling methods are developed via hydrophobic interactions, electrostatic association with the particles coating, ligand coordination such as thiols and histidines and nickel mediated assembly of histidine to carboxyl groups.

The aim of this study was to develop a protocol for the conjugation of bone and cartilage specific Abs to be able to monitor ECM formation in $3 \mathrm{D}$ tissue engineered constructs. The probes have been developed considering that they should provide enhanced contrast in imaging modalities such as MRI, micro-CT or nuclear imaging for which transparency of the construct does not form an issue. Therefore, the conjugation chemistry should be compatible with particles that could be applied as contrast agents. Here, we chose to optimize and test anti-collagen-I and anticollagen-II Abs conjugated with fluorescent probes as a proof of concept. We have validated the binding specificity with collagen type-I and collagen type-II on collagen type-I coated glass slides, native cartilage and bone tissue sections and on $3 \mathrm{D}$ tissue engineered constructs. We show that our conjugation protocol provides a sufficient DOL retaining an adequate antibody-antigen binding affinity to detect ECM components.

\section{Materials and methods}

\subsection{Ab-dye conjugation procedure}

Anti-collagen type-I (ab34710, Abcam $\left.{ }^{\circledR}\right)$ and anticollagen type-II (ab34712, Abcam ${ }^{\circledR}$ ) (both polyclonal, produced in rabbit), the dyes ATTO 488 NHS-ester (ATTO-TEC GmbH) and ATTO-594 NHS-ester (ATTO-TEC GmbH) and Zeba ${ }^{\mathrm{TM}}$ Micro Spin Desalting Columns ( $40 \mathrm{~K}$ MWCO, $75 \mu \mathrm{l}$, Thermo Fisher Scientific) were used. Prior to use, the buffer in the columns was exchanged to phosphate buffered saline (PBS) with $0.02 \mathrm{M}$ sodium azide according to manufactures instruction. Sodium azide was used as a preservative to inhibit the growth of contaminants such as bacteria or fungi in the antibody solutions. Before the conjugation step, $10 \mu \mathrm{l}$ of antibody solution was passed through the column once in order to exchange the antibody buffer solution to PBS solution. The product was collected in an amber colored $1.5 \mathrm{ml}$ eppendorf tube. To adjust the $\mathrm{pH}$ to the optimal conjugation value $(\mathrm{pH}=8.3)$, sodium bicarbonate $(1 \mathrm{M}, \mathrm{pH}=8.3)$ was added to the antibody solution. On the first use, the dye was dissolved to $2 \mathrm{mg} \mathrm{ml}^{-1}$ in anhydrous DMSO according to manufactures instruction, aliquot and stored at $-20{ }^{\circ} \mathrm{C}$ for further experiments. In order to obtain the desired DOL between 2 and 3 labels per antibody (higher DOL results in nonfunctional antibodies), approximately $0.1 \mu \mathrm{l}$ of dye solution were added to the antibody solution, mixed and incubated for $1 \mathrm{~h}$ at RT with continuous shaking 
on an oscillating $x-y$ plate. The conjugate solution was then passed three times through new desalting columns to remove any unconjugated dye. An ND100 spectrophotometer (Nanodrop Technologies, USA) was utilized to analyze the obtained concentration and ensure that the reaction occurred as expected. If required, BSA was added to increase the solution concentration above $1 \mathrm{mg} \mathrm{ml}^{-1}$. The anti-collagen type-I conjugated ATTO 488 dye will further be referred to as 'anti-col-I'. The anti-collagen type-II conjugated ATTO 594 dye will further be referred to as 'anti-col-II'. The conjugate solution was stored at $4{ }^{\circ} \mathrm{C}$. As positive control to assess conjugates functionality, the same anti-collagen type-I or type-II antibody and a secondary anti-rabbit antibody conjugated to an Alexa-Fluor 488 fluorophore were used in several experiments as a positive control and will be further referred to as 'control probe'.

\subsection{Conjugate characterization}

The efficiency of the procedure and DOL of the antibody-dye conjugate were determined with a ND1000 spectrophotometer (Nanodrop Technologies, USA). The following equation (equation (1)), based on the Lambert-Beer law, was applied to calculate the DOL:

$$
\begin{aligned}
\mathrm{DOL} & =\frac{[\text { dye }]}{\text { [protein }]}=\frac{A_{\max } / \varepsilon_{\max }}{A_{\text {prot }} / \varepsilon_{\text {prot }}} \\
& =\frac{A_{\max } / \varepsilon_{\text {prot }}}{\left(A_{280}-A_{\max }{ }^{*} \mathrm{CF}_{280}\right)^{*} \varepsilon_{\max }},
\end{aligned}
$$

where: $A_{280}$ is the absorbance at $280 \mathrm{~nm}, A_{\max }$ is the absorbance at $\lambda_{\max }, \lambda_{\max }$ is the wavelength where the absorbance reaches its maximal value, CF is the correction factor which depends on the dye's spectral properties, $\varepsilon_{\text {prot }}$ is the molar extinction coefficient $\left(\mathrm{M}^{-1} \mathrm{~cm}^{-1}\right)$ of the pure protein at $280 \mathrm{~nm}$ and $\varepsilon_{\max }$ is the molar extinction coefficient $\left(\mathrm{M}^{-1} \mathrm{~cm}^{-1}\right)$ of the dye at its absorbance maximum. According to literature, an ideal DOL sets between 2 and 8 depending on the materials and methods utilized. Thus, we aimed at a practical DOL of 4. SDS-PAGE was applied to get an impression of the purity of the conjugate. The gel was run at $70 \mathrm{~V}$ for stacking and then shifted to $30 \mathrm{~mA}$ until separation was completed.

\subsection{Scaffold fabrication}

Scaffolds were fabricated as described before, from 300PEOT55PBT45 (300/55/45) (PolyVation, The Netherlands), a block copolymer composed of poly (ethylene oxide terephthalate) (PEOT) and poly(butylene terephthalate) (PBT) with a weight ratio of 55-45 for the two components, respectively, and a molecular weight (MW) of the starting poly(ethylene glycol) (PEG) segments of $300 \mathrm{Da}$ used in the co-polymerization process [30].

For electrospun (ES) scaffolds, a $28 \%(\mathrm{w} / \mathrm{v})$ solution of $300 / 55 / 45$ was prepared in a mixture of chloroform
$\left(\mathrm{CHCl}_{3}\right)$-1,1,1,3,3,3-hexafluoro-2-propanol (HFIP) with a volume ratio of 78:22. The solution was left stirring at room temperature overnight. Subsequently, the solution was loaded into a syringe and pumped at a controlled flow rate using a syringe pump (KDS 100, KD Scientific). PTFE tubing was used to connect the syringe and a needle to which a high voltage was applied (Gamma High Voltage Research Inc., FL, USA). A stainless steel collector, covered by aluminum foil, was used to collect the ES scaffold. A voltage of $12 \mathrm{kV}$ was applied to a $1.2 \mathrm{~mm}$ needle, which was placed at $25 \mathrm{~cm}$ from the collector. The flow rate was set at $15 \mathrm{ml} \mathrm{h}^{-1}$, temperature to $25^{\circ} \mathrm{C}$, and humidity to $30 \%$. Upon reaching a sheet thickness of approximately $200 \mu \mathrm{m}$ the electrospinning process was stopped and disks with a diameter of $15 \mathrm{~mm}$ were punched out from the sheet.

Additive manufacturing by means of fused deposition modeling with a bioscaffolder (SysENG, Germany) was used to fabricate 3D plotted scaffolds, as described before [31, 32]. The cylindrical shaped scaffolds had diameter of $8 \mathrm{~mm}$ a height of $3 \mathrm{~mm}$, a fiber-to-fiber distance of $1000 \mu \mathrm{m}$, a fiber diameter of approximately $200 \mu \mathrm{m}$, and a layer thickness of $150 \mu \mathrm{m}$.

\subsection{Cell culture}

Bone marrow aspirates were obtained from donors after written informed consent and human bone marrow stromal cells (hMSCs) were isolated and proliferated as previously described [33]. In short, 20 gauge needles were used to re-suspend the aspirates, which were then plated

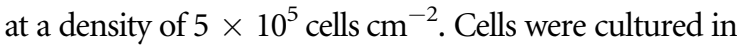
hMSC proliferation medium, for which the composition is described in the supplementary data is available online at stacks.iop.org/BMM/13/044102/mmedia, at $37^{\circ} \mathrm{C}$ in a humid atmosphere with $5 \% \mathrm{CO}_{2}$. The culture medium was refreshed three times a week. After monolayer expansion, cells were either cryopreserved or used for further subculturing. Passage $3 \mathrm{hMSCs}$ were detached from the culture flasks by trypsinization upon reaching $70 \%$ confluence. Basic medium contained $\alpha$-minimal essential medium (Life Technologies), 10\% heat-activated fetal bovine serum (Cambrex), $0.2 \mathrm{mM}$ ascorbic acid (Asap; Life Technologies), $2 \mathrm{mM}$ L-glutamine (Life Technologies), 100 units $\mathrm{ml}^{-1}$ penicillin (Life Technologies), $10 \mu \mathrm{g} \mathrm{ml}^{-1}$ streptomycin (Life Technologies). Proliferation medium consisted of basic medium supplemented with $1 \mathrm{ng} \mathrm{ml}^{-1}$ basic fibroblast growth factor (Neuromics, Acris Antibodies, Germany). Osteogenic medium consisted of basic medium supplemented with $10 \mathrm{nM}$ dexamethasone. Chondrogenic medium contains Dulbecco's modified essential medium (D-MEM) (Life Technologies) with $0.2 \mathrm{mM}$ ascorbic acid, 100 units $\mathrm{ml}^{-1}$ penicillin (Life Technologies), $10 \mu \mathrm{g} \mathrm{ml}^{-1}$ streptomycin (Life Technologies), $50 \mu \mathrm{g} \mathrm{ml}^{-1}$ ITS-premix, $100 \mu \mathrm{g} \mathrm{ml}^{-1}$ sodium pyruvate, $10 \mathrm{ng} \mathrm{ml}^{-1} \mathrm{TGF}-\beta 3$ and $1 \mu \mathrm{M}$ dexamethasone. TGF- $\beta 3$ and dexamethasone 


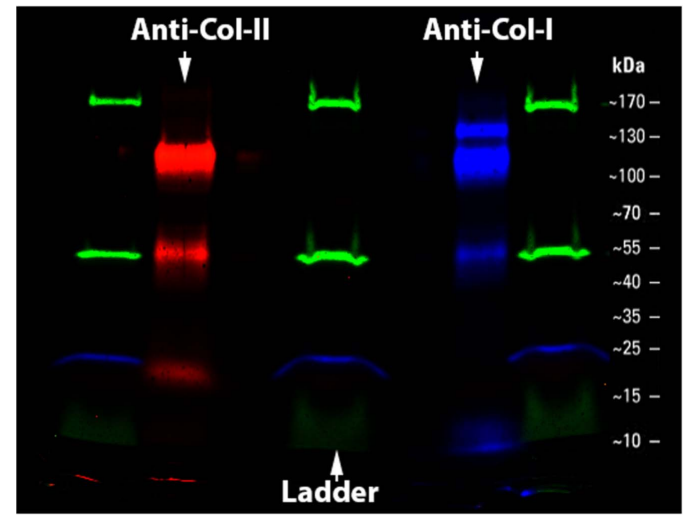

Figure 2. SDS page was run for anti-col-I and anti-col-II conjugates. The ladders were placed in the first (1), third (3) and fifth (5) lane and their fluorescent bands are displayed in green. Anti-col-II was located on the second column (2) and is displayed in red. Anti-col-I was located in the fourth column and is displayed in blue.

were freshly added every time that the media was changed during culture.

All scaffolds were sterilized by immersion in $70 \%$ ethanol for at least $2 \mathrm{~h}$, washed multiple times with sterile PBS and subsequently placed into a non-treated 24 well plate (NUNC). The constructs were then incubated at $37^{\circ} \mathrm{C}$ in a humid atmosphere with $5 \% \mathrm{CO}_{2}$ overnight in basic medium to pre-wet them. To prevent the ES scaffold discs from floating, rubber O-rings (Eriks BV, The Netherlands) were used to hold the discs in place. After incubation, the medium on the scaffold was aspirated, and 75000 cells and 250000 cells were seeded onto each ES scaffold and plotted scaffolds, respectively. After $7 \mathrm{~d}$ of culture in proliferation medium, the media was replaced with chondrogenic and osteogenic medium to start differentiation and cultured for additional $14 \mathrm{~d}$.

\subsection{Immunostaining}

Glass slides with a diameter of $18 \mathrm{~mm}$ were immersed in $10 \%$ acetic acid in ethanol for $30 \mathrm{~min}$, followed by $100 \%$ ethanol rinses and dried in the oven at $50{ }^{\circ} \mathrm{C}$. Collagen type I from rat tail (BD Biosciences, Two Oak Park. Bedford, USA) was diluted from a stock concentration of 11.59 to $2 \mathrm{mg} \mathrm{ml}^{-1}$ in a $0.02 \mathrm{M}$ acetic acid solution. Glass slides were placed in a non-treated 12 well plate (NUNC) and $250 \mu \mathrm{l}$ of collagen solution was added. After $1 \mathrm{~h}$ incubation at $37^{\circ} \mathrm{C}$, glass slides were washed three times with PBS to remove any remaining acetic acid. Prior to Ab incubation, slides were blocked with a buffer $(0.1 \%$ Triton X-100, $1 \%$ BSA in PBS). Afterwards, they were incubated with the fluorescently conjugated primary Abs, at $4{ }^{\circ} \mathrm{C}$, overnight. After incubation, slides were washed three times with PBST (0.1\% Tween-20 in PBS) for 5 min each. The presence of collagen coating was further confirmed by picosirius red staining (supplementary figure $1(\mathrm{C})$ ).

A 6 weeks old post-mortem rat was kindly provided by the department of Biomedical Signals and
Systems (BSS, MIRA institute, University of Twente). Animal use was regulated by national laws on animal experiments after approval from a local ethical committee. The tail and bone of the rat was isolated and immersed in $12.5 \%$ EDTA, $\mathrm{pH}=8$, for 5 weeks to decalcify the tissues. EDTA was changed three times a week. A series of increasing ethanol concentrations $(60 \%, 70 \%, 80 \%, 90 \%, 96 \%, 100 \% \times 2), 2 \mathrm{~d}$ per concentration, was used to dehydrate the tissue. Subsequently, the tissue was immersed in butanol overnight and in eosin for $1 \mathrm{~h}$ to stain them with a pink color to be able to localize the sample after embedding. Specimens were embedded in paraffin for $5 \mathrm{~d}$ in a holder at $60{ }^{\circ} \mathrm{C}$. Paraffin was changed after $2 \mathrm{~d}$ to remove any traces of butanol. The sections were cut at room temperature with $5 \mu \mathrm{m}$ intervals. Prior to Ab incubation, specimens were blocked with a buffer $(0.1 \%$ Triton $\mathrm{X}-100,1 \% \mathrm{BSA}$ in PBS). Incubation was performed with the fluorescently conjugated primary Abs, at $4{ }^{\circ} \mathrm{C}$, overnight. After incubation, specimens were washed three times with PBST for 5 min each. Afterwards, specimens were incubated in a solution of $0.1 \%$ Sudan Black B in 70\% Ethanol for 20 min to mask bone autofluorescence and washed three times with PBS for 5 min each.

After $14 \mathrm{~d}$ of culture in differentiation media, the cultured samples were washed once with PBS, fixed with paraformaldehyde (4\% in PBS) for $15 \mathrm{~min}$ and stored in PBS at $4{ }^{\circ} \mathrm{C}$. Prior to $\mathrm{Ab}$ incubation, constructs were blocked with a buffer $(0.1 \%$ Triton X-100, $1 \%$ BSA in PBS). Samples were incubated with both anti-col-I and anti-col-II Abs, at $4{ }^{\circ} \mathrm{C}$ overnight. Control samples were incubated with primary Abs (ab34710 and ab34712, Abcam ${ }^{\circledR}$ ), at room temperature, for $1 \mathrm{~h}$. Then, constructs were washed once with PBS and incubated with the corresponding secondary antibody (anti-rabbit antibody conjugated to an Alexa-Fluor 488 fluorophore) overnight, at $4{ }^{\circ} \mathrm{C}$. After incubation, constructs were washed three times with PBST (0.1\% Tween-20 in PBS) for 5 min each. Afterwards, samples were incubated in a solution of $0.1 \%$ Sudan Black B in 70\% Ethanol for 20 min to remove polymer autofluorescence and then washed three times with PBS for 5 min each. Cell nuclei labeling was performed with $4^{\prime}, 6^{\prime}$ Diamidin-2'-phenylindoldihydrochlorid (DAPI, $100 \mathrm{ng} \mathrm{ml}^{-1}$ in PBS, Sigma) and actin filaments were stained with Phalloidin to visualize the cytoskeleton. Samples were imaged using a Nikon A1 confocal microscope (Nikon Instruments Inc.).

\section{Results and discussion}

\subsection{Ab and dye concentration by spectrophotometry}

To quantify the DOL after conjugation of the fluorescent probe to the $\mathrm{Ab}$, the absorbance spectrum was analyzed with a ND1000 spectrophotometer 

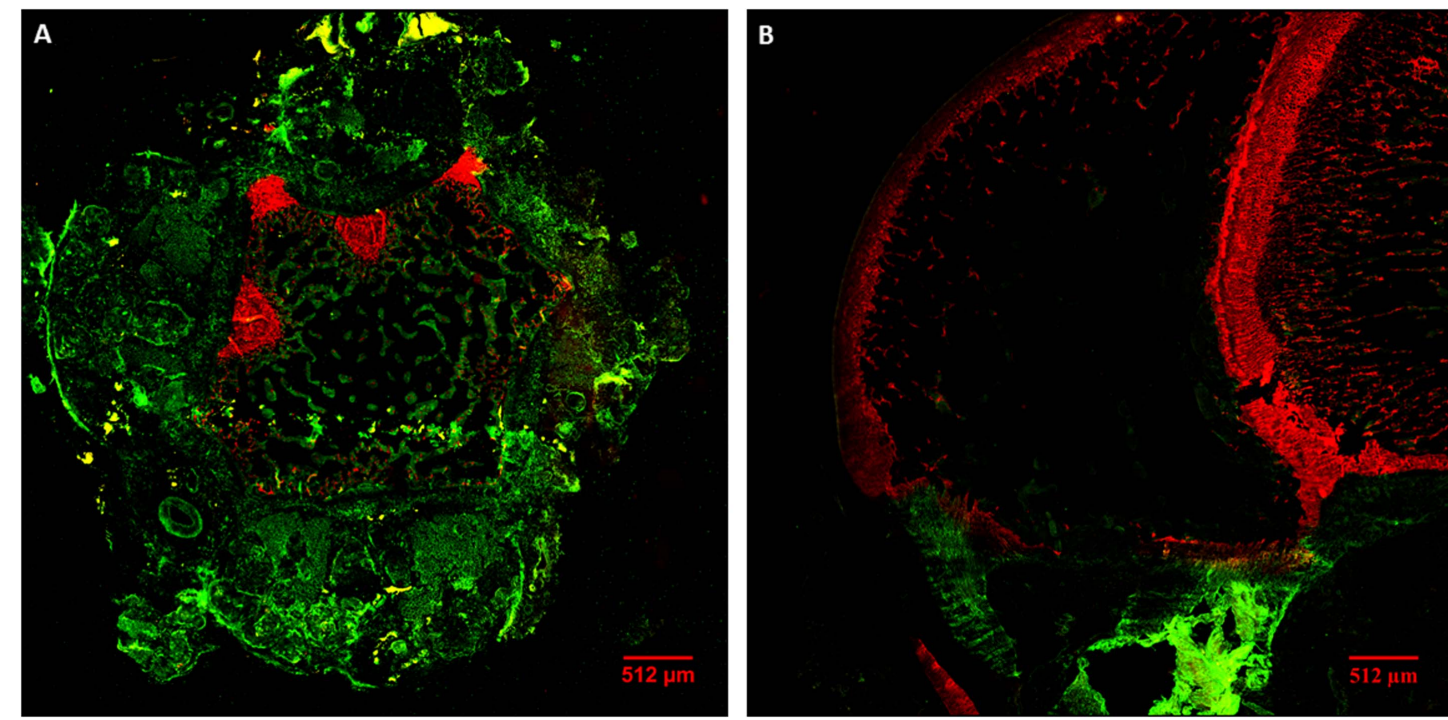

Figure 3. Fluorescent microscopy images of (A) tail and (B) bone sections, stained by anti-col-I (green) and anti-col-II (red). Scale bar: $512 \mu \mathrm{m}$.

(Nanodrop Technologies, USA). The CFs for ATTO 488 and for ATTO 594 were provided by the supplier and found to be 0.1 and 0.51 , respectively. The $\varepsilon_{\max }$ for ATTO 488 and for ATTO 594 were also provided by the supplier and were 90000 and $120000 \mathrm{M}^{-1} \mathrm{~cm}^{-1}$, respectively. The molar extinction coefficient for the $\mathrm{AB}$ (IgG) was set at $210000 \mathrm{M}^{-1} \mathrm{~cm}^{-1}$. The path length in all measurements was set at $1 \mathrm{~cm}$. For the anti-col-I the $A_{280}$ was found to be 0.877 , while $A_{\max }$ was found to be 1.953 at approximately $500 \mathrm{~nm}$. With these values the DOL was determined according to equation (1) and found to be around 6. For, anti-col-II conjugated to ATTO 594 the $A_{280}$ was found to be 2.115 , while $A_{\max }$ was found to be 0.435 at approximately $500 \mathrm{~nm}$. With these values the DOL was determined according to equation (1) and found to be around 4 . Both values are well under the optimal range for DOL which sets between 2 and 8. An excessively high DOL may denature the antibodies or reduce its antigen-binding activity, decreasing its functionality. A low DOL will result in a low signal. Further analysis of the probe functionality will be accessed in the following section.

SDS-PAGE was performed before adding BSA to the conjugate solution to get insight in the purity of the probes solution (figure 2). In both antibody conjugated dyes, a strong fluorescent band was observed in the top of the gel, where higher MW molecules were retained. Two other bands were observed at lower MW. However, these bands seemed significantly weaker compared to the ones in the top layer of the gel. The probe solution was therefore considered sufficiently purified with just low amounts of unconjugated label and Abs.

\subsection{Cell culture}

The ultimate goal of the probe developed here was to be applied on culture systems to monitor and characterize tissue formation in $3 \mathrm{D}$ scaffolds in vitro. Firstly, the antigen affinity of the anti-col-I was assessed on a pure collagen type-I coating (Rat) and compared to the affinity of the commercially available control probe (supplementary figure 1). It was observed that both probes showed high binding affinity with the collagen coating whereas no label was detected on the surface of the glass slide. This was done to ensure that the functionality of both conjugated probes was preserved. The different net charges of the fluorophore $(-1)$ and the amine groups $(+1)$ and the possibility of fluorophore conjugation to the $\mathrm{Ab}$ antigen-site could have reduced its final functionality, even though the DOL was well between optimal values. Anti-col-I and anti-col-II were further tested on a histological section of demineralized rat tail and bone tissue to get insights in non-specific binding (figure 3), further confirming the successful synthesis of the molecular probes. All structures were blocked with a BSA based blocking buffer to prevent nonspecific binding and secondary Abs were applied to probe successful blockage (supplementary figure 3 ). Moreover, both control probes and anti-col-I and anti-col-II showed similar detection sites (supplementary figure 3).

The two probes were, then, applied on hMSCs cultured for $14 \mathrm{~d}$ in osteogenic or chondrogenic medium on ES and 3D plotted scaffolds (figure 4). ES scaffolds showed randomly oriented fibers with a non-uniformly distributed average diameter of $3.06 \pm 1.95 \mu \mathrm{m}$, with a minimum diameter of approximately $1 \mu \mathrm{m}$ and maximum fiber diameter of $8 \mu \mathrm{m}$. Conversely, 3D plotted 


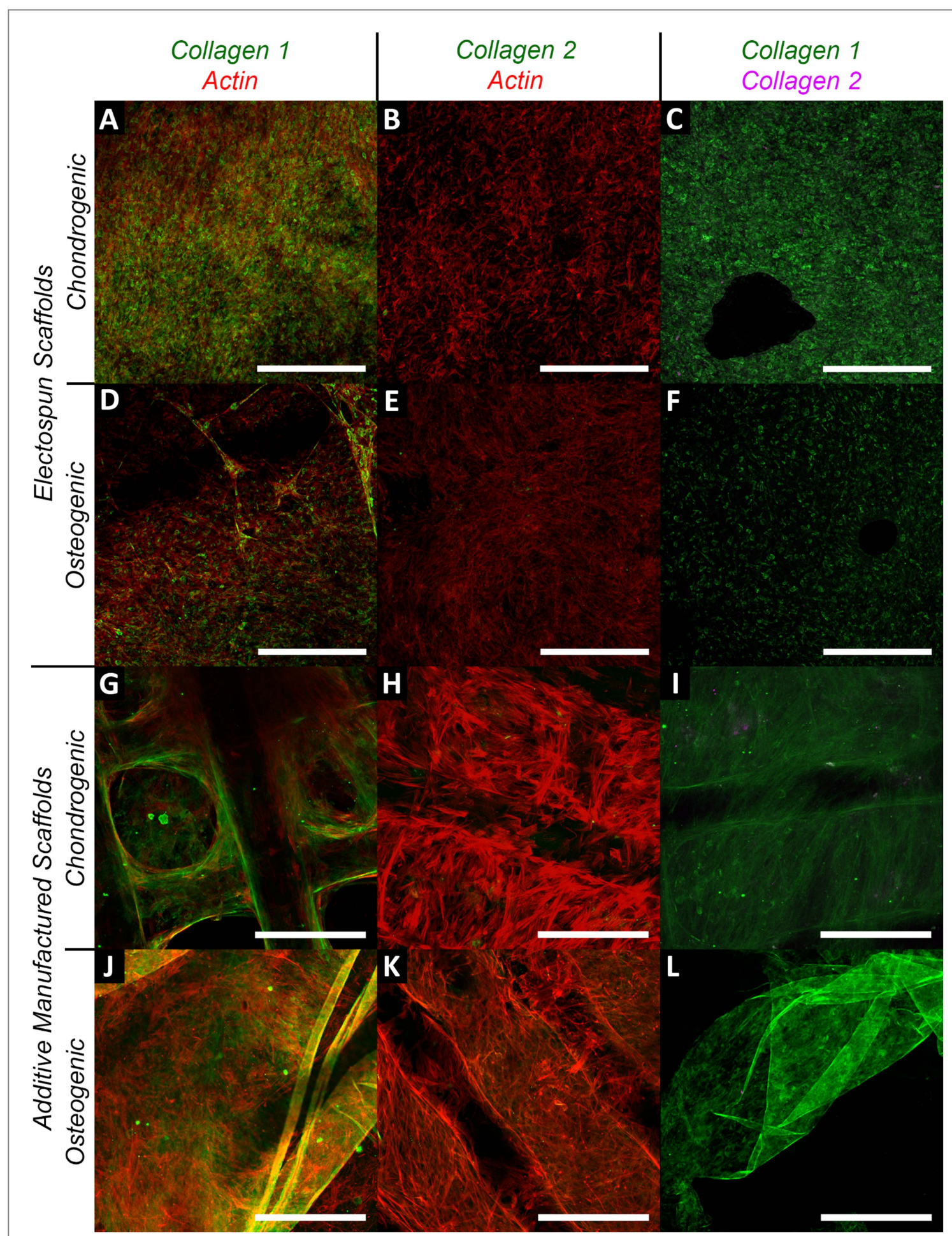

Figure 4. Fluorescent microscopy images of hMSCs cultured in (A)-(F) electrospun and (GL) 3D plotted scaffolds in chondrogenic (A)-(C), (G)-(I) and osteogenic (D)-(F), (J)-(L) media, showing collagen type I and collagen type II staining. In all four conditions (A), (D), (G) and (J) collagen type I (green) is found with similar signal intensities as the actin counterstain (red), whereas collagen type II was hardly detected compared to actin (B), (E), (H), (K). (C), (F), (I), (L) When staining collagen type I (green) and collagen type II $\mathrm{i}$ (purple) it can clearly be observed that collagen type I is more abundant for all conditions. The scale bars represent (A)-(F) $1 \mathrm{~mm}$ and (G)-(L) $500 \mu \mathrm{m}$.

scaffolds showed well oriented fibers with an average fiber diameter of $214.5 \pm 27.1 \mu \mathrm{m}$ and a fiber spacing of $498.4 \pm 46 \mu \mathrm{m}$.

Results showed that collagen type I was abundantly produced by hMSCs in both scaffold types and in both media. Collagen type II was hardly expressed in osteogenic medium and minimally produced in chondrogenic medium in both scaffold types, thus suggesting better differentiation in osteogenic conditions than in chondrogenic conditions. In our previous studies, we have also found similar results at a genetic level, where it was clear that hMSCs on PEOT/ PBT scaffolds showed upregulated early markers for both osteogenesis and chondrogenesis, accompanied 
by higher expression of alkaline phosphatase activity and glycosaminoglycans, respectively [30].

The anti-co-II probe was also tested against a control probe in osteogenic conditions on 3D plotted scaffolds (supplementary figure 2). The circular pattern formed by the seeded hMSCs has shown to be typical for tissue formation in this type of scaffolds, where cells initially attach on the struts of the scaffolds and over time close the pore. This pattern of tissue growth is one of the processes that can be considered important to assess during culture to monitor the type and morphology of the ECM that was produced. Collagen type-I was found both with anti-col-I and with the control probe. In both samples, the collagen type-I showed to be distributed over the areas where cells were located as well. Therefore, the newly developed probes of this study can be considered successfully applied. The high DOL obtained in this study could have interfered with the binding affinity of the $\mathrm{Ab}$ to the antigen, which could explain the lower brightness of the anti-col-I compared to the control probe. The stability of the label was not expected to result in this lower brightness, since the ATTO-dyes applied in anticol-I and anti-col-II are generally more stable than the fluorophore coupled the control probe. Yet, there are some other advantages for the conjugated antibodies. They do not require a secondary incubation with a secondary antibody labeled antibodies, which reduces the amount of protocol steps and unspecific secondary antibody binding. These conjugated-antibodies allow the use of two or more antibodies raised in the same animal, e.g. useful in this study due to the limited availability of collagen II antibodies. Finally, they allow the conjugation of any fluorophore or nanoparticle with a NHS-ester, especially important in cases in which they are not commercial available and readily conjugated for secondary incubation.

In theory, the conjugation chemistry applied on this $\mathrm{Ab}$ allows for the coupling to any other kind of labeling particle, thus being applicable also to the near infrared spectrum. Applying other imaging modalities would permit imaging of collagens at greater depths without the need to stain the cells. By coupling collagen type detection to a responsive scaffold material, for example a sort of actuating system to locally administer certain stimuli, more insight in collagen production and collagen orientation could be realized.

\section{Conclusion}

The main objective of this study was the optimization and validation of a method that could be used to functionalize particles and fluorophores to be applied in several imaging modalities. Based on a concise review on Abs and available conjugation strategies, the most promising method for application in 3D tissue engineered scaffolds was chosen and optimized. Both anti-collagen type-I and anti-collagen type-II Abs were successfully conjugated to their respective dyes. The anti-col-I probe showed a similar selectivity to a control probe targeting collagen type-I in all tests performed, whereas anti-col-II revealed no maturation of chondrogenic differentiation of hMSCs in both ES and 3D plotted scaffolds. Yet, from the successful collagen type-I and type II detection, we conclude that the conjugation via amines offers an easy and feasible chemistry to obtain specific anticollagen-I and -II Abs coupled to several types of fluorophores and particles.

\section{Acknowledgments}

The authors gratefully acknowledge funding from the Netherlands Institute for Regenerative Medicine (NIRM) through the grant number FES0908.

\section{ORCID iDs}

Lorenzo Moroni (iD https://orcid.org/0000-0003$1298-6025$

\section{References}

[1] von der Mark K and Conrad G 1979 Cartilage cell differentiation: review Clin. Orthopaedics Relat. Res. 139 185-205

[2] Leferink A M, van Blitterswijk C A and Moroni L 2016 Methods of monitoring cell fate and tissue growth in threedimensional scaffold-based strategies for in vitro tissue engineering Tissue Eng. B 22 265-83

[3] Appel A A, Anastasio M A, Larson J C and Brey E M 2013 Imaging challenges in biomaterials and tissue engineering Biomaterials 346615-30

[4] Washburn N R, Weir M, Anderson P and Potter K 2004 Bone formation in polymeric scaffolds evaluated by proton magnetic resonance microscopy and x-ray microtomography J. Biomed. Mater. Res. A 69A 738-47

[5] Chesnick I E, Avallone F A, Leapman R D, Landis W J, Eidelman N and Potter K 2007 Evaluation of bioreactorcultivated bone by magnetic resonance microscopy and FTIR micro spectroscopy Bone 40 904-12

[6] Burry R W 2011 Controls for immunocytochemistry: an update J. Histochem. Cytochem. 59 6-12

[7] Ansell S M, Harasym T O, Tardi P G, Buchkowsky S S, Bally M B and Cullis P R 2000 Antibody conjugation methods for active targeting of liposomes Methods Mol. Med. 25 51-68

[8] Asti A, Visai L, Dorati R, Conti B, Saino E, Sbarra S, Gastaldi $G$ and Benazzo F 2008 Improved cell growth by BioOss/PLA scaffolds for use as a bone substitute Technol. Health Care 16 401-13

[9] Hofer T, Skeffington L R, Chapman C M and Rader C 2009 Molecularly defined antibody conjugation through a selenocysteine interface Biochemistry 48 12047-57

[10] Lichlyter D J, Grant S A and Soykan O 2003 Development of a novel FRET immunosensor technique Biosens. Bioelectron. 19 219-26

[11] Trier N H, Hansen P R and Houen G 2012 Production and characterization of peptide antibodies Methods 56 136-44

[12] Shinomiya Y, Kato N, Imazawa M and Miyamoto K 1982 Enzyme immunoassay of the myelin basic protein J. Neurochem. 39 1291-6 
[13] King T P and Kochoumian L 1979 A comparison of different enzyme-antibody conjugates for enzyme-linked immunosorbent assay J. Immunol. Methods 28 201-10

[14] Liopo A, Conjusteau A, Tsyboulski D, Ermolinsky B, Kazansky A and Oraevsky A 2012 Biocompatible gold nanorod conjugates for preclinical biomedical research J. Nanomed. Nanotechnol. S2

[15] Karmani L et al 2013 Antibody-functionalized nanoparticles for imaging cancer: influence of conjugation to gold nanoparticles on the biodistribution of ${ }^{89} \mathrm{Zr}$-labeled cetuximab in mice Contrast Media Mol. Imaging 8 402-8

[16] Robinson J M, Takizawa T, Vandre D D and Burry R W 1998 Ultrasmall immunogold particles: important probes for immunocytochemistry Microsc. Res. Tech. 42 13-23

[17] Paik C H, Ebbert M A, Murphy P R, Lassman C R, Reba R C, Eckelman W C, Pak K Y, Powe J, Steplewski Z and Koprowski H 1983 Factors influencing DTPA conjugation with antibodies by cyclic DTPA anhydride J. Nucl. Med. 24 1158-63

[18] Shu CY et al 2008 Conjugation of a water-soluble gadolinium endohedral fulleride with an antibody as a magnetic resonance imaging contrast agent Bioconjugate Chem. 19651-5

[19] Rieger M, Schaumann G E, Mouvenchery Y K, Niessner R, Seidel M and Baumann T 2012 Development of antibodylabelled superparamagnetic nanoparticles for the visualisation of benzo[a]pyrene in porous media with magnetic resonance imaging Anal. Bioanal. Chem. 403 2529-40

[20] Zhang Y, Hong H, Engle J W, Bean J, Yang Y, Leigh B R, Barnhart T E and Cai W 2011 Positron emission tomography imaging of CD105 expression with a ${ }^{64} \mathrm{Cu}$-labeled monoclonal antibody: NOTA is superior to DOTA PLoS One 6 e28005

[21] Gupta S, Batra S and Jain M 2014 Antibody labeling with radioiodine and radiometals Methods Mol. Biol. 1141 147-57

[22] Theilacker N, Roller E E, Barbee K D, Franzreb M and Huang X 2011 Multiplexed protein analysis using encoded antibodyconjugated microbeads J. R. Soc. Interface 8 1104-13

[23] Shrestha D, Bagosi A, Szollosi J and Jenei A 2012 Comparative study of the three different fluorophore antibody conjugation strategies Anal. Bioanal. Chem. 404 1449-63

[24] Acchione M, Kwon H, Jochheim C M and Atkins W M 2012 Impact of linker and conjugation chemistry on antigen binding, Fc receptor binding and thermal stability of model antibody-drug conjugates $m A b s 4362-72$

[25] Brinkley M and Brief A 1992 Survey of methods for preparing protein conjugates with dyes, haptens, and cross-linking reagents Bioconjugate Chem. 32-13

[26] Dhar T K, Dasgupta S, Ray D and Banerjee M 2012 A filtration method for rapid preparation of conjugates for immunoassay J. Immunol. Methods $38571-8$

[27] Wilbur D S, Stray J E, Hamlin D K, Curtis D K and Vessella R L 1994 Monoclonal-antibody fab' fragment cross-linking using equilibrium transfer alkylation reagents-a strategy for sitespecific conjugation of diagnostic and therapeutic agents with $\mathrm{F}(\mathrm{Ab})(2)$ fragments Bioconjugate Chem. 5 220-35

[28] Algar W R, Tavares A J and Krull U J 2010 Beyond labels: a review of the application of quantum dots as integrated components of assays, bioprobes, and biosensors utilizing optical transduction Anal. Chim. Acta 673 1-25

[29] Lao U L, Mulchandani A and Chen W 2006 Simple conjugation and purification of quantum dot-antibody complexes using a thermally responsive elastin-protein $\mathrm{L}$ scaffold as immunofluoresecent agents J. Am. Chem. Soc. 128 14756-7

[30] Leferink A M, Santos D, Karperien M, Truckenmuller R K van Blitterswijk C A and Moroni L 2015 Differentiation capacity and maintenance of differentiated phenotypes of human mesenchymal stromal cells cultured on two distinct types of 3D polymeric scaffolds Integr. Biol. 7 1574-86

[31] Moroni L, de Wijn J R and van Blitterswijk C A 2005 Threedimensional fiber-deposited PEOT/PBT copolymer scaffolds for tissue engineering: influence of porosity, molecular network mesh size, and swelling in aqueous media on dynamic mechanical properties J. Biomed. Mater. Res. A 75 957-65

[32] Leferink A M, Chng Y C, van Blitterswijk C A and Moroni L 2015 Distribution and viability of fetal and adult human bone marrow stromal cells in a biaxial rotating vessel bioreactor after seeding on polymeric $3 \mathrm{D}$ additive manufactured scaffolds Frontiers Bioeng. Biotechnol. 3169

[33] Both S K, Van der Muijsenberg A J C, Van Blitterswijk C A, De Boer J and Bruijn J D D 2007 A rapid and efficient method for expansion of human mesenchymal stem cells Tissue Eng. 13 3-9 